\title{
CHEMOSPHERE
}

\section{Anaerobic digestion of polyelectrolyte flocculated waste activated sludge}

\author{
C.P. Chu ${ }^{\text {a }}$, D.J. Lee ${ }^{\mathrm{a}, \mathrm{c}, *}$, Bea-Ven Chang ${ }^{\mathrm{b}}$, C.H. You ${ }^{\mathrm{b}}$, C.S. Liao ${ }^{\mathrm{b}}$, J.H. Tay ${ }^{\mathrm{c}}$ \\ ${ }^{a}$ Department of Chemical Engineering, National Taiwan University, Taipei 10617, Taiwan \\ ${ }^{\mathrm{b}}$ Department of Microbiology, Soochow University, Taipei 111, Taiwan \\ ${ }^{\mathrm{c}}$ Division of Environmental and Water Resources Engineering, School of Civil and Environmental Engineering, \\ Nanyang Technological University, Singapore 639798
}

Received 5 August 2002; received in revised form 21 May 2003; accepted 21 May 2003

\begin{abstract}
This work examined how adding one of three polyelectrolyte flocculants (T3052: cationic, T2000: non-ionic, and T1052: anionic) affected the anaerobic digestion of wastewater sludge. Methane production, floc characteristics (morphology and $\zeta$-potential) and process parameters (soluble chemical oxygen demands (SCODs) and reductive potentials) were monitored along the digestion tests. The digestion rates of T2000- and T1052-conditioned sludge resembled that for original sludge. The T3052-flocculated sludge generated methane at a higher rate during the first 6 days of digestion than did the original one. In the following stage, the digestion rate of sludge flocculated with T3052 at dosage exceeding $15 \mathrm{~g} / \mathrm{kg}$ dried solids declined. For example, at 40 days of digestion the methane production amounts for original, $15 \mathrm{~g} / \mathrm{kg}$ DS flocculated, and $40 \mathrm{~g} / \mathrm{kg}$ flocculated sludge were of 136,105 , and $85 \mathrm{~g} / \mathrm{kg} \mathrm{DS}$, respectively. The role of flocculants could change in different stages of digestion.

The dosed polymers had no apparent toxicity to the inoculum used. The changes in SCOD, adenosintriphosphate concentrations, oxidative and reductive potential, and $\zeta$-potentials did not correlate with the noted hindered digestion for T3052-conditioned sludge. Microphotographic observation revealed that the flocs of T3052-conditioned sludge were not only of a large size, but also were resistant to structural deterioration during digestion. Therefore, mass transfer resistance was proposed to account for the hindered digestion efficiency observed for T3052-conditioned sludge.
\end{abstract}

(c) 2003 Elsevier Ltd. All rights reserved.

Keywords: Digestion; Flocculation; Methane; Activated sludge; Size

\section{Introduction}

Anaerobic digestion is a widely used stabilization process for reducing sludge volume and producing biogas (Parkin and Owen, 1986). During the digestion process, effective inactivation of the pathogenic micro-

\footnotetext{
${ }^{*}$ Corresponding author. Address: Department of Chemical Engineering, National Taiwan University, Taipei 10617, Taiwan. Tel.: +886-2-2362-5632/2363-5230; fax: +886-2-2302-3040/ 2362-3040.

E-mail address: djlee@ccms.ntu.edu.tw (D.J. Lee).
}

organisms can be achieved (Carrington et al., 1991; Gavaghan et al., 1993; Stadterman et al., 1995; Jepsen et al., 1997).

Chemical flocculants are added to sludge to enhance its sedimentation rate before digestion. The flocculant dose leading to the fastest settling is referred to as the "optimal dose". Though the weight fraction of polyelectrolyte in the conditioned slurry is generally small, Dentel et al. (2000) demonstrated that the applied polyelectrolyte may be attached onto and carried out with the conditioned sludge at an amount up to $10 \mathrm{~kg} /$ ton dry solids (DS). Although the fraction of polyelectrolyte in the sludge is small, its role on the performance 
of subsequent treatment/disposal processes has not been satisfactorily examined. Chu et al. (2000, 2001) reviewed that flocculating sludge to charge neutralization point could markedly enhance the rate of subsequent thermal pyrolysis process.

Controversial results were reported with respect to the role of chemical conditioners on the anaerobic digestion of sludge. Gossett et al. (1978) noted that methane production and volatile solids destruction ratio were reduced in an anaerobic digested wastewater sludge in the presence of organic coagulant. El-Mamouni et al. (1998) found that the synthetic polyelectrolyte not only has no inhibition effects to biomass activity, but also could enhance the metabolite transfer rate and reduce the inhibition of acetogenic and methanogenic bacteria in an upflow anaerobic sludge blanket reactor. Discrepancy clearly exists in the literature works on the role of organic conditioner on methane production.

This work investigates the role of polyelectrolyte flocculant on the anaerobic digestion efficiency of wastewater waste activated sludge. We monitored the methane production together with the changes in floc characteristics and process parameters during digestion. Some observations on the influence of floc size on digestion efficiency were made.

\section{Experimental}

\subsection{Sample and flocculation conditioning}

Waste activated sludge was taken from a wastewater treatment plant in the Presidential Enterprise Co., Taoyuan, Taiwan. Sludge sediment after 1-h settling was the test material. The dried solids of this material was measured as 9390 mg/l. Accupyc Pycnometer 1330 (Micromeritics, USA) was used to measure the density of dried solid in sludge, giving a result of $1470 \mathrm{~kg} / \mathrm{m}^{3}$ with a relative deviation of less than $0.5 \%$. The $\mathrm{pH}$ value of original sludge was approximately 6.7.

Cationic polyelectrolyte T3052, non-ionic flocculant T2000, and anionic polyelectrolyte T1052 were provided by Kai-Guan Inc., Taiwan. The physical properties of these polymers were listed in Table 1. These polymers exhibited a similar molecular weight but a very different surface charge. Sludge sample was first placed in a mixing vessel equipped with a paddle mixer. Flocculant solution $(0.2 \% \mathrm{w} / \mathrm{w})$ was then gradually poured into the mixing vessel with $200 \mathrm{rpm}$ of stirring for $5 \mathrm{~min}$, followed by $50 \mathrm{rpm}$ for another $20 \mathrm{~min}$. The flocculation stage did not notably change the $\mathrm{pH}$ value of the suspension.

\subsection{Anaerobic digestion and related tests}

Anaerobic digestion of the sludge was conducted following the procedure proposed by Chang et al. (1996, 1998). The compositions of the gas in the glove box were maintained at $99 \% \mathrm{~N}_{2}, 0.05 \% \mathrm{O}_{2}, 0.75 \% \mathrm{~N}_{2}, 0.01 \% \mathrm{CH}_{4}$ and $0.2 \% \mathrm{CO}_{2}$, to simulate an anaerobic environment in nature. Eight millilitres sludge (original or flocculated) mixed with $1 \mathrm{ml}$ anaerobes and $1 \mathrm{ml}$ medium (compositions as listed in Table 2) were added to the serum bottles. Chang et al. (1998) isolated strains from the sediment at 12 sites of Tam-Shui River in Taipei County degrading organics to produce products including methane. The one collected at site eight, named strain $\mathrm{K} 8$, had the highest methane productivity among the other strains. Since this paper aimed at exploring the implications of polyelectrolyte flocculation of sludge to its methane productivity during anaerobic digestion, the $\mathrm{K} 8$ strain was used as the seed microorganisms in subsequent digestion tests.

Serum bottles were then capped with butyl rubber stoppers and wrapped in aluminum foil to prevent possible photolysis. The bottles were incubated at $35^{\circ} \mathrm{C}$ without shaking. Chang et al. (1996, 1998) recommended $35{ }^{\circ} \mathrm{C}$ as the optimal temperature at which anaerobes grew, which was used in digestion tests. At each sample time (day 2, 4, 6, 8, etc.) three serum bottles were removed from the batch of 400 bottles total, analyzed,

Table 2

The components of medium used during incubation

\begin{tabular}{ll}
\hline Components & Concentration $(\mathrm{g} / \mathrm{l})$ \\
\hline $\mathrm{K}_{2} \mathrm{HPO}_{4}$ & 0.35 \\
$\mathrm{KH}_{2} \mathrm{PO}_{4}$ & 0.27 \\
$\mathrm{NH}_{4} \mathrm{Cl}$ & 2.7 \\
$\mathrm{CaCl}_{2} \cdot 2 \mathrm{H}_{2} \mathrm{O}$ & 0.1 \\
$\mathrm{MgCl}_{2} \cdot 2 \mathrm{H}_{2} \mathrm{O}$ & 0.1 \\
$\mathrm{FeCl}_{2} \cdot 6 \mathrm{H}_{2} \mathrm{O}$ & 0.02 \\
Yeast extract & 12 \\
Reszurin (reductants) & 0.001 \\
\hline
\end{tabular}

Table 1

The properties of polyelectrolyte flocculants used in this study

\begin{tabular}{lllll}
\hline & Components & Ionic property & Molecular weight & Charge density \\
\hline T3052 & Polyacrylamide & Cationic & $10^{7}$ & $20 \%$ \\
T2000 & Polyacrylamide & Non-ionic & $5 \times 10^{6}$ & - \\
T1300 & Polyacrylamide & Anionic & $10^{7}$ & $40 \%$ \\
\hline
\end{tabular}


and discarded. The mean results from these analyses were used to represent data with standard deviation calculated as less than $1 \%$. For comparison, anaerobic digestion tests on pure flocculant solution $(0.2 \%)$ were also undertaken to demonstrate the biodigestability of the flocculant.

\subsection{Characterization of the sludge}

A particle sizer (LS230, Coulter) measured the volume average floc size using light scattering technique. The volume average floc size of original sludge was approximately of $58 \mu \mathrm{m}$. The $\zeta$-potentials of sludge flocs were measured by a zetameter (Zeta-Meter System 3.0, Zeta-Meter Inc., USA). The result for original sludge was $-13.6 \mathrm{mV}$. The $\zeta$-potential of sludge did not change much in the presence of anaerobe K8. The surface charges of sludge flocculated with T3052 would be neutralized at a dose of approximately $10-15 \mathrm{~g} / \mathrm{kg}$ DS. For the T2000- or T1052-flocculated sludge, the surface charge remained unchanged or became more negative after flocculation. The microscopic photographs were obtained with the assistance of a phase contrast microscope (ECLIPSE E800, Nikon) at a magnification of $400 \times$.

Methane production was quantified with a gas chromatography (Sigma 3B Perkin-Elmer) equipped with a packed column $(200 \times 0.5 \mathrm{~cm}, 80 / 100$ porapal Q; Supecol, Bellefonte, PA) and flame-ionization detector. Column temperature was kept at $90^{\circ} \mathrm{C}$ while those for injector and the detector were set at $55^{\circ} \mathrm{C}$. Nitrogen at a flow rate of $20 \mathrm{ml} / \mathrm{min}$ was the carrying gas. Integrator (HP3396 Series II) was used to integrate the peak area, hence quantifying the methane concentration.

The oxidative and reductive potential (ORP) of the sludge was measured with an ORP meter (HI 9017 Hanna). Total chemical oxygen demand (TCOD) of the sludge was measured with direct reading spectrophotometer (DR/2000, HACH, USA). The TCOD of original sludge (with $\mathrm{K} 8$ and the medium) was measured as $7990 \mathrm{mg} / \mathrm{l}$. The chemical oxygen demand of the filtrate was measured and is referred from here to as soluble chemical oxygen demand (SCOD), which was read as $479 \mathrm{mg} / \mathrm{l}$ for the original sample.

\subsection{ATP measurement}

The Luceferin-Luciferase method was utilized to quantitatively measure the adenosintriphosphate (ATP) concentrations in the sludge. The ATP concentration was an index for the microbial density level in the suspension. An aliquot of activated sludge sample (premixed with $\mathrm{K} 8$ and medium) of $0.5 \mathrm{ml}$ was automatically pipetted along with the necessary reagents into a cuvette. The reagents used here include NRB (extracting ATP from the microbial cell) and LUMIT PM (luciferase dissolved in LUMIT buffer solution). The enzymesubstrate complex, luciferase-luciferin, converted the chemical energy associated with ATP into light, and a luminometer (BIOCOUNTER M 2500, LUMAC, The Netherlands) measured the emitted bioluminescence light in the relative luminescence units (RLUs).

Using the tests with standard ATP solutions, $1 \mu \mathrm{g} / \mathrm{l}$ of ATP yielded a light intensity of 1036 RLU. The ATP concentration in the suspension containing only the anaerobe $\mathrm{K} 8$ (without sludge) was $0.42 \mu \mathrm{g} / \mathrm{l}$. All the other testing samples reported herein were the sludge (original or flocculated) mixed with $\mathrm{K} 8$ and the medium.

\section{Results}

\subsection{Methane production}

Figs. 1 and 2 depict the methane production amount as function of digestion time.

Fig. 1 illustrates the methane productions of the original sludge (without flocculants) and the three flocculants solutions (without sludge) under investigation $(0.2 \% \mathrm{w} / \mathrm{w})$. The methane gas production was expressed in unit of $\mathrm{g} \mathrm{CH}_{4} / \mathrm{kg}$ DS. As Fig. 1 reveals, the methane production increased with time, indicating the progress of the digestion process. For the original sludge, the methane production increased to nearly $75 \mathrm{~g} / \mathrm{kg}$ DS in 10 days. Chang et al. (2000) demonstrated that the polyelectrolyte flocculant could be partially digested under aerobic and anaerobic conditions. However, the methane generated from digestion of sample containing only

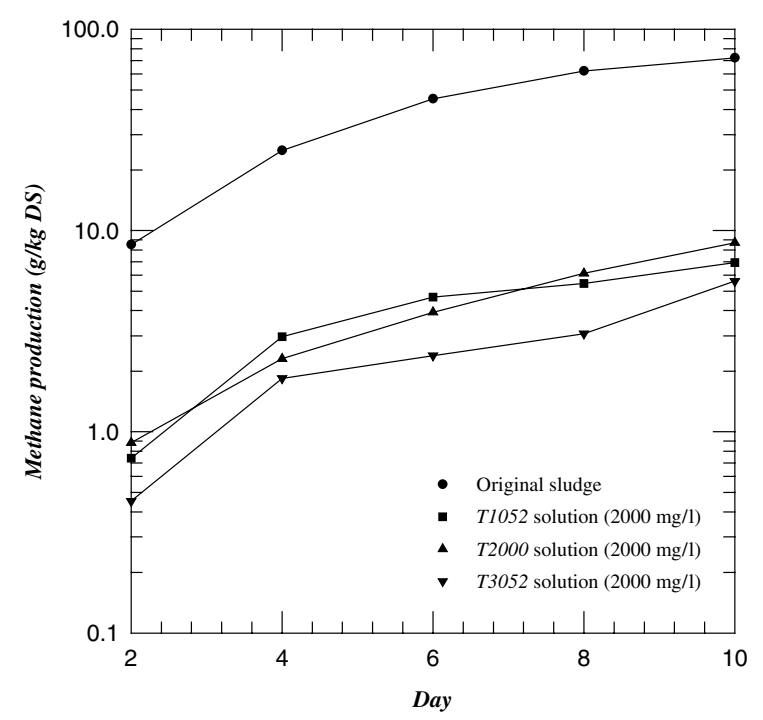

Fig. 1. Methane production amount for anaerobic digestion of original sludge and three flocculants. 

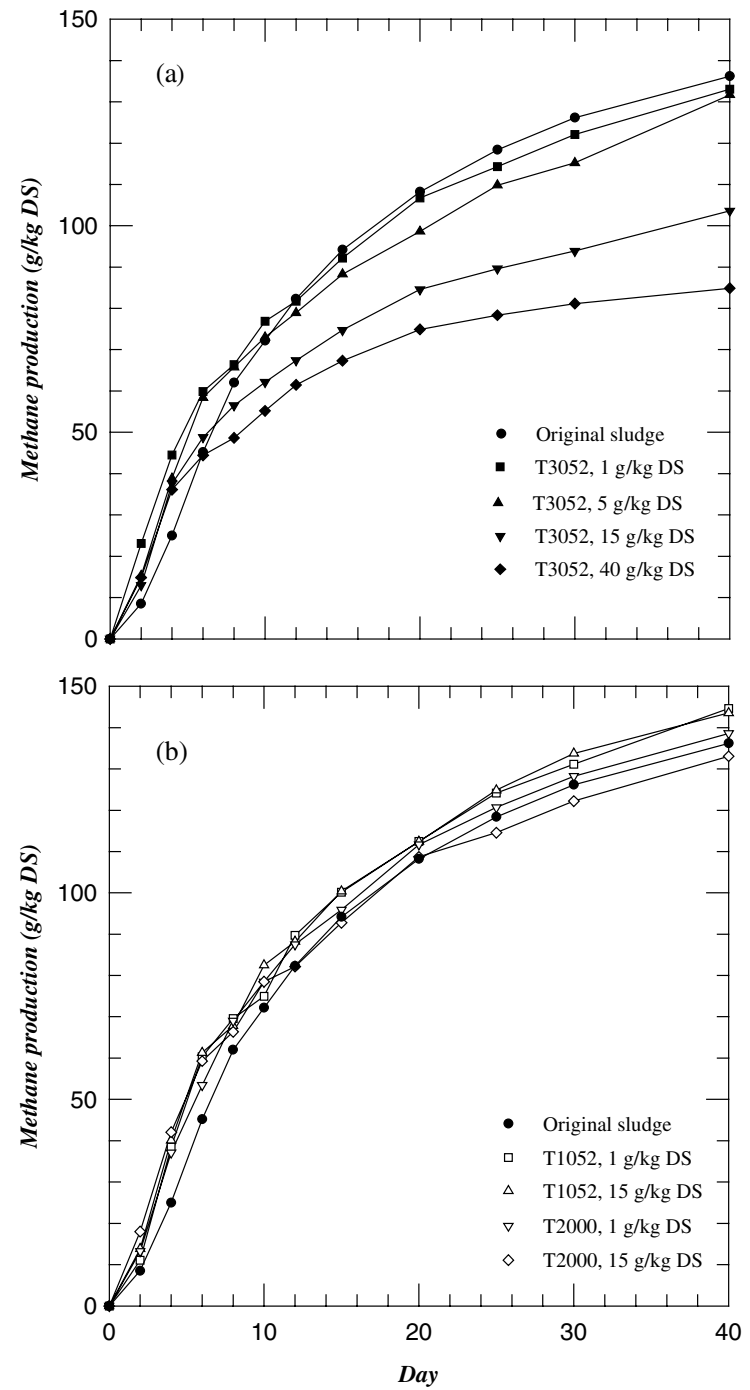

Fig. 2. Methane production amount for anaerobic digestion of sludge: (a) the original and T3052-flocculated sludge; (b) T1052-, and T2000-flocculated sludge.

flocculant polymer was only $5 \%$ in amount of that from digestion of unconditioned (original) sludge. The contribution of anaerobic digestion of flocculants to the methane production could hence be ignored in the subsequent tests.

Fig. 2(a) illustrates the methane production amounts for the original and the T3052-flocculated sludge. As Fig. 2(a) illustrates, during the first 6 days of digestion, the T3052-flocculated sludge generated methane at a higher rate than did the unconditioned sludge. As time elapsed, the digestion rate of sludge flocculated at dosage exceeding $15 \mathrm{~g} / \mathrm{kg}$ DS declined. After 10 days of digestion, the methane production for the original and the flocculated sludge at a dosage less than $5 \mathrm{~g} / \mathrm{kg}$ DS converged to a single curve. For example, at 40 days of digestion the methane production amounts for original, $1 \mathrm{~g} / \mathrm{kg}$ DS flocculated, and $5 \mathrm{~g} / \mathrm{kg}$ flocculated sludge were of 136,133 , and $132 \mathrm{~g} / \mathrm{kg}$ DS, respectively, which could be regarded identical considering the involved statistical errors. Meanwhile, the corresponding production for the $15 \mathrm{~g} / \mathrm{kg}$ DS flocculated and $40 \mathrm{~g} / \mathrm{kg}$ DS flocculated sludge generated methane only of 105 and $85 \mathrm{~g} / \mathrm{kg} \mathrm{DS}$, respectively, corresponding to a $23 \%$ and $38 \%$ reduction.

Fig. 2(b) demonstrates the methane production amounts from sludge flocculated with T1052 or with T2000. Resembling Fig. 2(b), digestion was enhanced compared to unconditioned sludge during the first 10 days. In the subsequent stages, however, all methane production curves converged to a common one, as demonstrated in the cases with T3052 flocculated sludge at a low polymer dose.

\subsection{Other tests}

During the digestion the methanogenic bacteria continuously transformed the soluble organic compounds into bio-gas that reduced the SCOD value, while the hydrolysis reaction by acetogenic bacteria kept replenishing it. In all tests the soluble COD in medium increased to a plateau value approximately $200-250 \%$ of its original value after 6 days of digestion (data not shown). The hydrolysis reaction dominated during the initial stage of digestion (up to 6 days). Afterward the rate of hydrolysis and the rate of methane production reached at a comparable level, hence with a nearly constant SCOD over time. The more flocculant that was added into the sludge, the higher level of SCOD could appear in the medium. After 10 days of digestion all SCOD/TCOD ratios approached a constant around $0.11-0.14$ (data not shown).

During anaerobic digestion the microorganisms reduced the ORP of the medium to a level suitable for volatile fatty acids and methane to form. Fig. 3 demonstrates the changes in ORP values during digestion. At the start of digestion the ORP values for the sludge samples ranged from -250 to $-200 \mathrm{mV}$. Meanwhile, the flocculation with T3052 yielded a less reductive environment (less negative initial ORP value for flocculated sludge).

As the digestion proceeded, the ORP soon became more negative in the first 4-6 days of digestion. For instance, the ORP for the original sludge and those flocculated with T1052 or T2000 dropped to a level of -320 to $-330 \mathrm{mV}$ in the 4 th to 6 th day, and then the trend reversed and the potential increased back to approximately -260 to $-290 \mathrm{mV}$. The high-dosed T3052 flocculated sludge experienced a much less drop in ORP value during the first 6 days. The ORP values for the sludge flocculated with T3052 at a dose of 15 or $40 \mathrm{~g} / \mathrm{kg}$ 

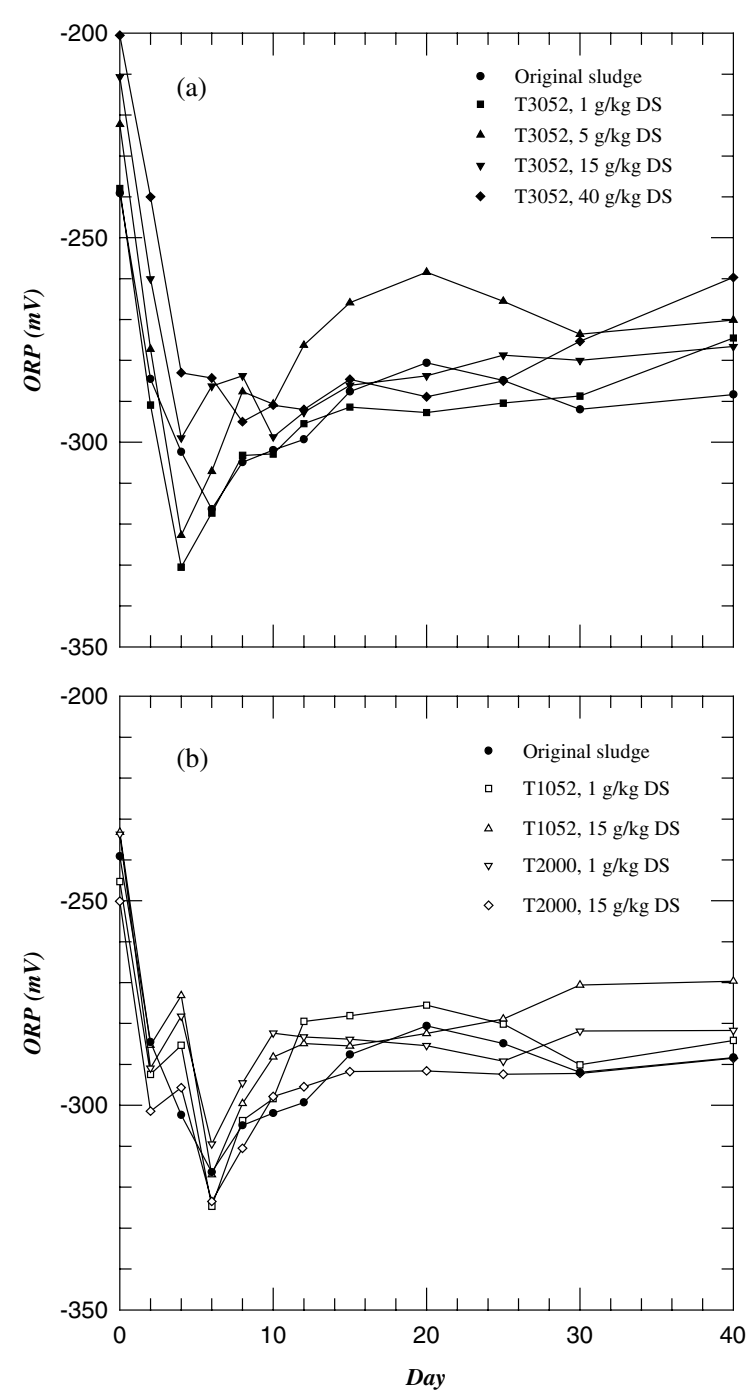

Fig. 3. Time evolution of oxidation-reduction potentials during the anaerobic digestion: (a) original and T3052-flocculated sludge, and (b) original, T1052-, and T2000-flocculated sludge.

DS merely dropped to a value around -280 to $-300 \mathrm{mV}$, and then reversed back.

A close correlation between the initial ORP drop and the methane production rate was noticeable. Restated, in the cases where the ORP in the 4th to 6th days dropped to lower than $-320 \mathrm{mV}$, the methane production would not be affected in the presence of the polyelectrolyte flocculant. After that, the polyelectrolyte appeared to hinder the digestion efficiency, as noted in the cases of high T3052 dosage (15 and $40 \mathrm{~g} / \mathrm{kg} \mathrm{DS}$ ).

Chang et al. (1996) proposed that the change in ORP might be attributed to the growth of anaerobic consortium in sludge. Fig. 4 demonstrates the measured ATP concentration, which represented the anaerobic consortium density level. In all tests the ATP
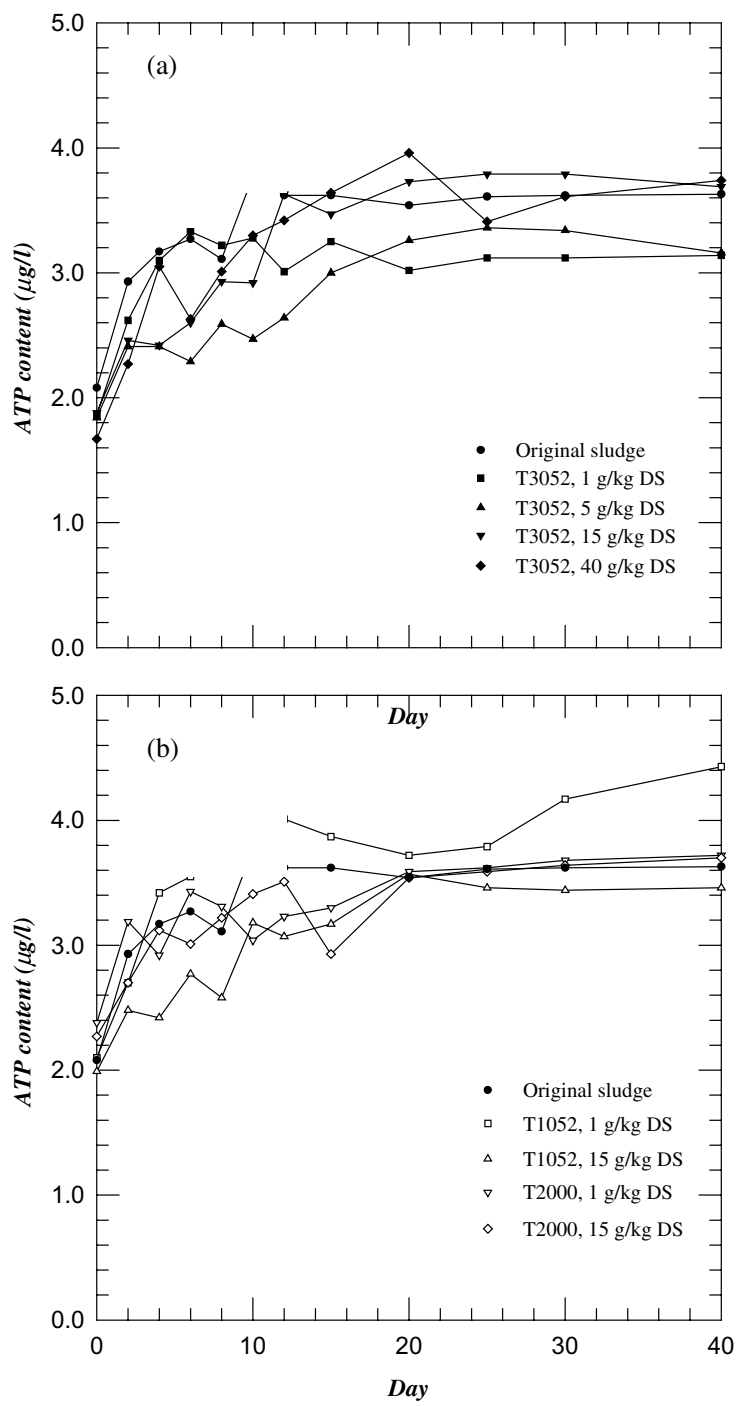

Fig. 4. Time evolution of ATP content during the anaerobic digestion: (a) original and T3052-flocculated sludge, and (b) original, T1052-, and T2000-flocculated sludge.

increased in concentration during the first 10 days and then reached a plateau value ranging 3-4 $\mu \mathrm{g} / \mathrm{l}$. No correlation with the presence of polymer flocculants to the microbial activity could hence be concluded. The present three flocculants had no apparent toxicity to the applied anaerobes K8. The distinct trends noted for ORP changes in Fig. 3 thereby could not be interpreted with the changes in growth phase of anaerobes.

Fig. 5 illustrates the time evolutions of the $\zeta$-potentials for sludge flocculated with the three polymers. The $\zeta$-potential of sludge was neutralized while conditioned with cationic flocculant T3052 at a dose among $5-15 \mathrm{~g} / \mathrm{kg}$ 

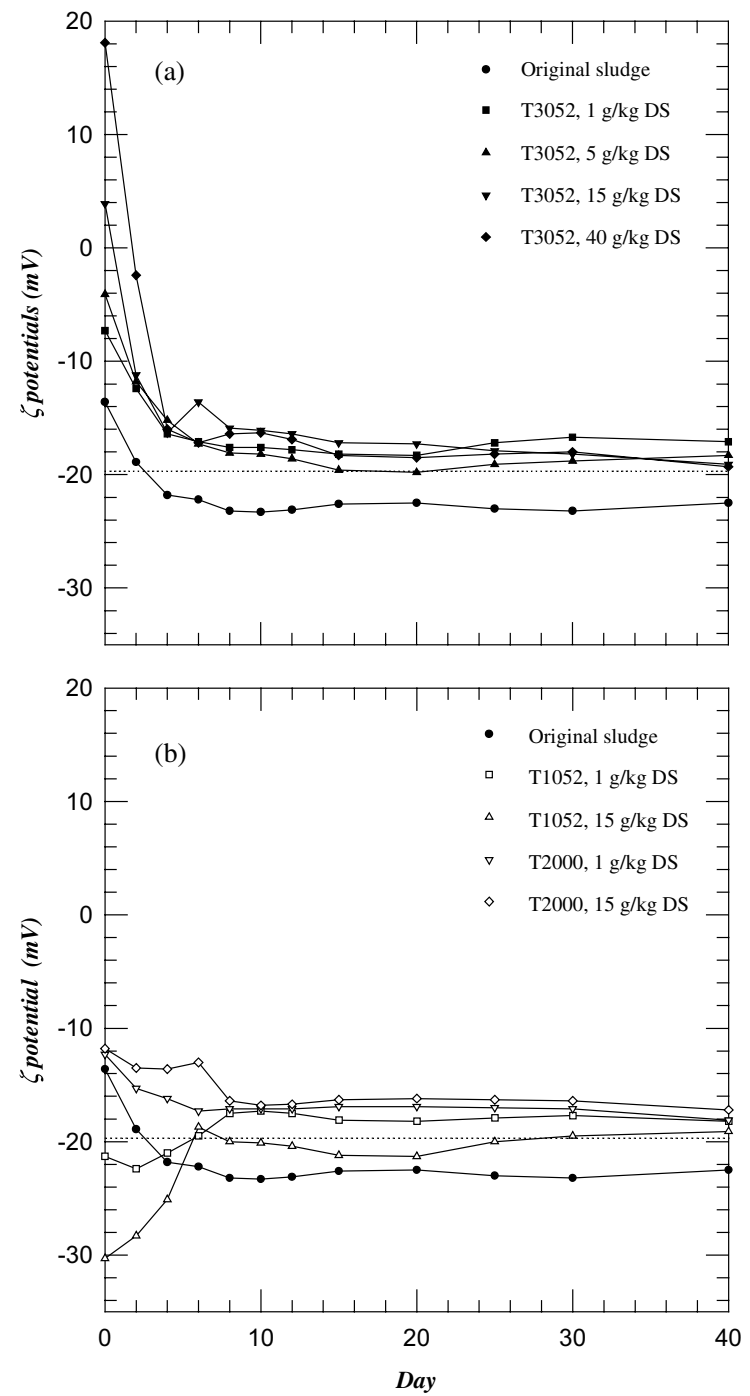

Fig. 5. The $\zeta$-potentials of sludge flocs during digestion: (a) original and T3052-flocculated sludges, and (b) original, T1052-, and T2000-flocculated sludges. The dash lines indicate the $\zeta$ potential of original sludge floc $(-19.7 \mathrm{mV})$ subject to sonication.

DS. For the other two polymers, the flocculation could not yield a less negatively charged particle surface.

As Fig. 5(a) and (b) demonstrate, the $\zeta$-potentials for all sludge samples gradually converged to approximately steady value of $-20 \mathrm{mV}$ regardless of polyelectrolyte flocculation. For example, the surface charges of original and of the T3052-flocculated sludge became more negative in the first 6 days. For the T1052-flocculated sludge whose initial surface charge was more negative than $-20 \mathrm{mV}$, the $\zeta$-potential became less negative in the first 6 days.

The original sludge samples after sonication treatment (without digestion) revealed a $\zeta$-potential of
$-19.8 \mathrm{mV}$. The fragments of the original sludge subject to 20-min sonication exhibited a similar surface charge as that for sludge digested for more than 6 days.

Figs. 6 and 7 demonstrate the microphotographs for the original and the T3052-flocculated sludge $(400 \times)$ prior to and after 30 days of anaerobic digestion. The photographs of T1052 and T2000-flocculated sludge (at $15 \mathrm{~g} / \mathrm{kg}$ DS) resembled those of original sludge and were omitted herein. The original sludge exhibited a loose floc structure with the presence of filamentous bacteria (Fig. 6(a)). After 30 days of digestion, partial disintegration of floc structure was noticeable (Fig. 6(b)). However, compared with the original sludge or the T1052 and T2000-flocculated ones, the flocs of T3052-flocculated
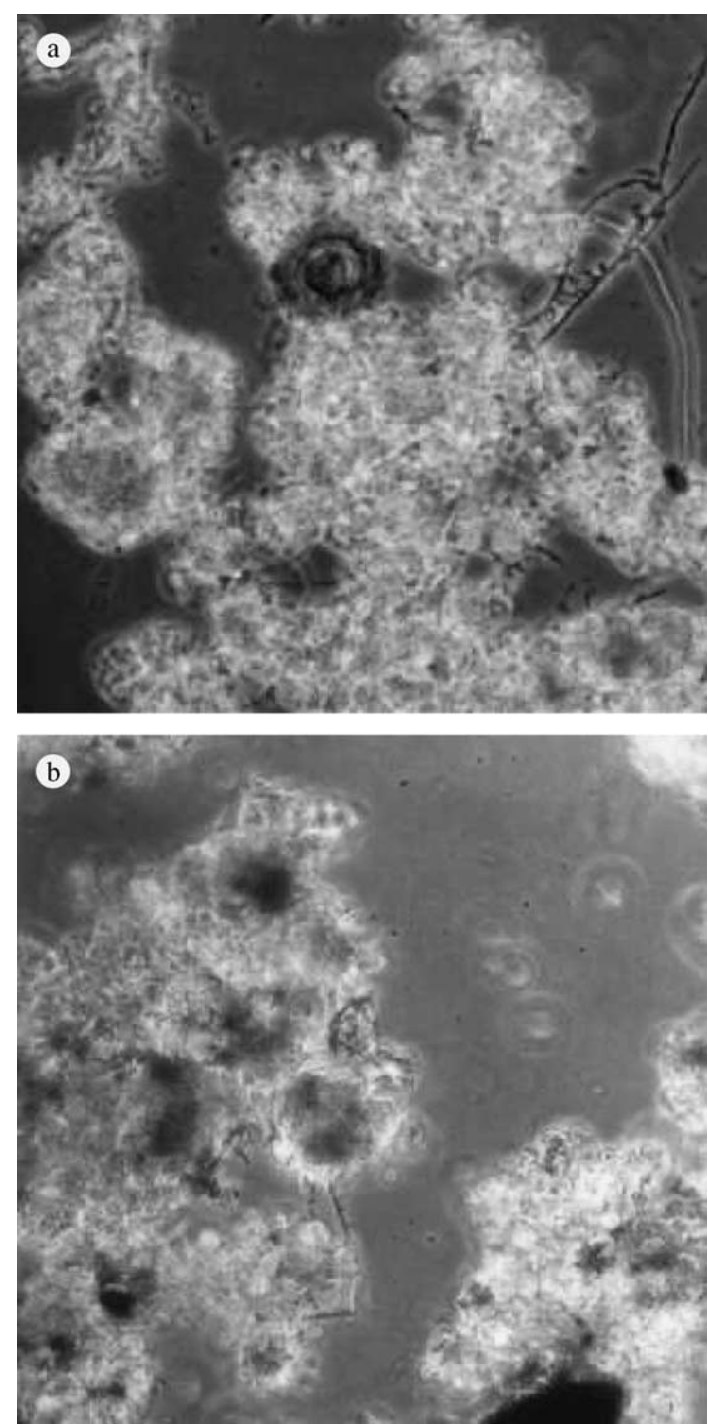

Fig. 6. The floc morphology of sludge during digestion $(400 \times)$ : (a) original sludge prior digestion, (b) original sludge after 30 days of digestion. 

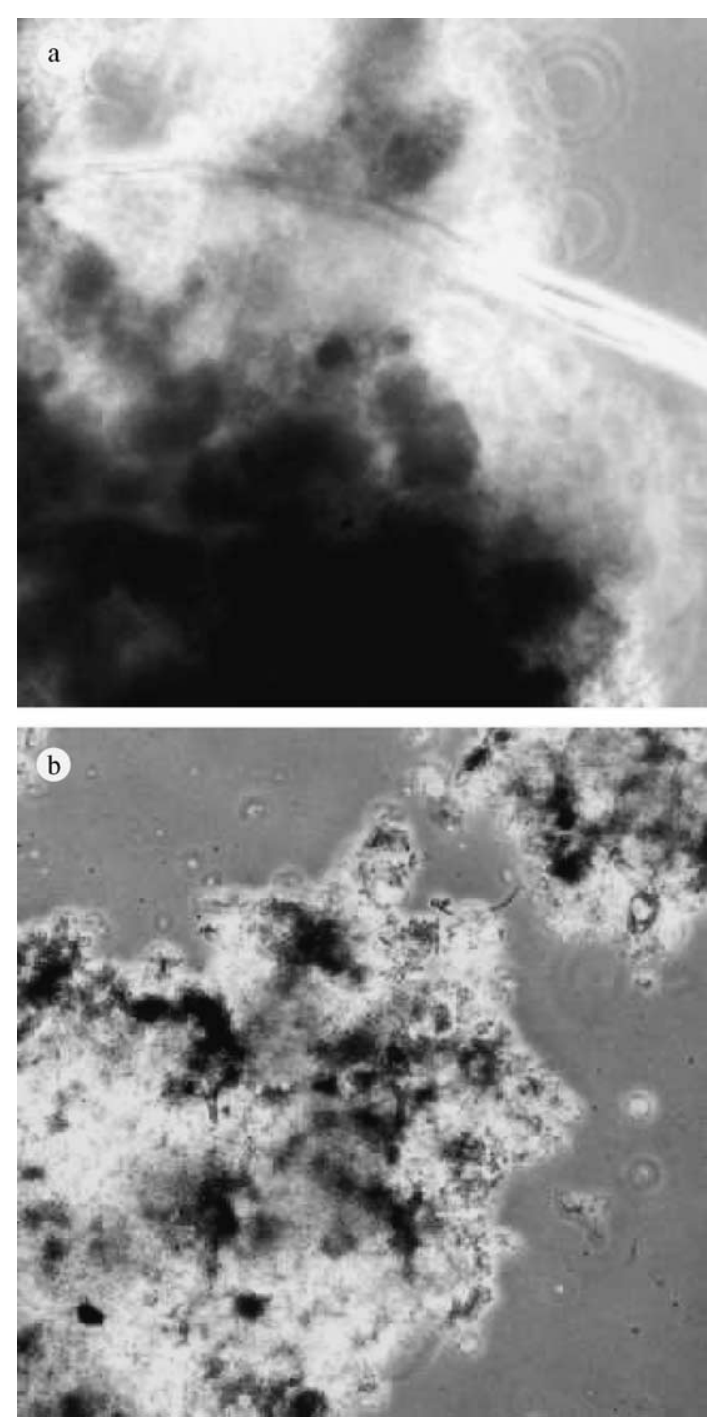

Fig. 7. The floc morphology of sludge during digestion $(400 \times)$. (a) T3052-flocculated sludge prior digestion, (b) T3052-flocculated sludge after 30 days of digestion.

sludge (15 g/kg DS) had an apparently larger size and denser structure (Fig. 7(a)). Although the degradation of flocs was apparent after 30 days of digestion, but the entire floc structure remained almost intact (Fig. 7(b)). Restated, the T3052-conditioned sludge not only exhibited a large floc size, but also resisted global structural deterioration during digestion.

\section{Discussion}

The above-mentioned experimental results clearly reveal that during the first stage of digestion ( $<6$ days) the presence of flocculants could enhance the digestion efficiency, which corresponded to the report of ElMamouni et al. (1998). In the following stages (>10 days), however, the flocculants would inhibit the progress of digestion process if the sludge were conditioned with cationic polymer to a high dosage. Such an observation correlated with the conclusions drawn by Gossett et al. (1978). This work demonstrated that the role of flocculants could change in different stages of digestion. Restated, it assisted methane production at the initial phase of digestion, but hindered the production at the later phase.

During the first stage the SCOD and ATP concentrations increased accordingly, the ORP dropped, and the $\zeta$-potentials of particle surface converged to a level of $-20 \mathrm{mV}$. Hence, the decomposition of flocculant facilitated the digestion. However, the ORP drops for T3052-flocculated samples at higher dosages were not so apparent as for the other sludges. In the following stage, the digestion was largely inhibited when the sludge was conditioned with T3052 at a high dosage. Based on the digestion tests with polymers (Fig. 1) the dosed polymers had no apparent toxicity to the inoculum. The SCOD, ATP concentrations, ORP, and $\zeta$-potentials all converged to a common value for all tests. These observations could not explain the noted hindered digestion for T3052-conditioned sludge.

Mass transfer resistance was hence proposed to account for the size-dependent digestion efficiency observed in Fig. 2(a). During anaerobic digestion the sludge would be first hydrolyzed to small molecules, like acetic acids or other long-chain organic acids (acidogenic stage). Then these short-chain compounds were decomposed to form methane (methanogenic stage). The greater floc size for T3052-flocculated sludge might prohibit efficient species movement within the sludge floc, which hindered the subsequent acidogenic and the methanogenic stages to produce methane. Such an occurrence also correlated with the smaller ORP drops for these sludge samples. Nonetheless, no direct experimental proof supported this hypothesis.

\section{Conclusions}

This work investigated the effects of polyelectrolyte flocculants on the anaerobic digestion of a wastewater sludge. Three polyelectrolytes at a similar molecular weight but different surface charge (cationic, non-ionic, and anionic) were tested. Only the cationic flocculant could efficiently condition the present sludge.

In the first stage of digestion ( $<6$ days) adding polyelectrolyte could enhance methane production, accompanied with the increases in SCOD and ATP concentration in the medium, and the drops in the ORP. The corresponding $\zeta$-potentials of particle surface quickly 
adapted themselves to approach a level of $-20 \mathrm{mV}$. During the following stage ( $>10$ days), while all the other conditioned sludge possessed a similar digestion characteristic to that for original sample, application of T3052 (cationic) at high dosage (>15 g/kg DS) could markedly inhibit the digestion efficiency. This may be attributable to its much greater floc size, thereby resisting efficient mass exchange within the sludge flocs.

\section{Acknowledgements}

DJL wishes to thank Nanyang Technological University for appointing him as a visiting professor during June-August, 2002. National Science Council of ROC financially supported this work.

\section{References}

Carrington, E.G., Pike, E.B., Auty, D., Morris, R., 1991. Destruction of faecal bacteria, enteroviruses and ova of parasites in wastewater biosolids by aerobic thermophilic and anaerobic mesophilic digestion. Water Science and Technology 24 (2), 377-380.

Chang, B.-V., Zheng, J.X., Yuan, S.Y., 1996. Effects of alternative electron donors and inhibitors on pentachlorophenol dechlorination in soil. Chemosphere 33, 313-320.

Chang, B.-V., Su, C.J., Yuan, S.Y., 1998. Microbial hexachlorobenzene dechlorination under three reducing conditions. Chemosphere 36, 2721-2730.

Chang, L.L., Raudenbush, D.L., Dentel, S.K., 2000. Aerobic and anaerobic biodegradability of a flocculant polymer.
In: Proc. 1st World Water Congress of Intl. Wat. Assoc. (IWA), Paris, vol. 4, pp. 242-249.

Chu, C.P., Lee, D.J., Chang, C.Y., 2000. Thermogravimetric analysis of activated sludge flocculated with polyelectrolyte. Journal of Environmental Engineering 126, 1082-1087.

Chu, C.P., Lee, D.J., Chang, C.Y., 2001. Thermal pyrolysis characteristics of polymer flocculated waste activated biosolids. Water Research 35, 49-56.

Dentel, S.K., Chang, L.-L., Raudenbush, D.R., Junnier, R.W., Abu-Orf, M.M., 2000. Influence of Polymer Chemistry on Biosolids and the Environment. Water Environment Research Foundation, Alexandria, VA.

El-Mamouni, R., Leduc, R., Guiot, S.R., 1998. Influence of synthetic and natural polymers on the anaerobic granulation process. Water Science and Technology 38 (8-9), 341347.

Gavaghan, P.D., Sykora, J.L., Jakubowski, W., Sorber, C.A., Sninsky, A.M., Lichte, M.D., Keleti, G., 1993. Inactivation of Giardia by anaerobic digestion of biosolids. Water Science and Technology 27 (3-4), 111-114.

Gossett, J.M., McCarty, P.L., Wilson, J.C., Evans, D.S., 1978. Anaerobic digestion of biosolids from chemical treatment. Journal of Water Pollution Control Federation 50, 533-542.

Jepsen, S.E., Krause, M., Gruttner, H., 1997. Reduction of fecal streptococcus and salmonella by selected treatment methods for biosolids and organic waste. Water Science and Technology 36 (11), 203-210.

Parkin, G.F., Owen, W.F., 1986. Fundamentals of anaerobic digestion of wastewater biosolids. Journal of Environmental Engineering 112, 867-920.

Stadterman, K.L., Sninsky, A.M., Sykora, J.L., Jakubowaki, W., 1995. Removal and inactivation of Cryptosporidium oocysts by activated biosolids treatment and anaerobic digestion. Water Science and Technology 31 (5-6), 97104. 